\title{
Contemporary and Practicable Technique to Produce Electricity using Waves
}

\author{
D. Rajalakshmi, R. Priya, N. Arun
}

\begin{abstract}
Ocean waves are huge, large untapped energy resources and the potential for extracting energy from waves is considerable. Ocean wave energy can play a dynamic role for producing electricity as fresh source of renewable energy to the off-grid power connection in remote areas. There are number of research work going across and around the coastlineto generate electrical energy from the ocean waves. Wave energy conversion technologies are important and lead to more research work in future. Wave energy converters converts the mechanical energy obtained from ocean waves to electricity. Researches in this area are driven for the need to meet demand in electricity but it is relatively immature compared to other renewable energy technologies. This proposed paper aims to develop a prototype that can utilize the wave energy to produce electricity. Wave energy generator has been developed and the results are analysed for different specifications of converter and also presented. From the experimental setup it is assured that slowly varying power generation is obtained from ocean wave. This paper also comprises working and main components of the system.
\end{abstract}

\section{INTRODUCTION}

Waves are produced by the transfer of energy fromexterior winds to the sea. The energy transfer rate depends upon speed of wind and the distance of interaction between wind and water. This wave power is used for electricity generation, water desalination or the pumping of water into reservoirs. A machine which is to feat wave power is called as a wave energy converter. It showed energy absorption dependency on load and more concentration in the design and constructionof the wave energy converter.[1] It investigated the peak power, the translator speed, and the variance of the power at different sea states and for different levels of damping. [2] The wavebuoy interaction was modelled with linear potential wave theory and the generator was modelled as a non-linear mechanical damping function that is dependent on piston velocity and electric load. [3] It showed how the absorbed power had varied as a function of significant wave height. [4] It described the fundamental ideas behind the concept for wave energy conversion and concluded mechanical parts should be kept as simple as possible and that overloads originating in the intermittent nature of the waves should be handled electrically rather than mechanically. [5] It reviewed technologies used in WEC.[6] It investigated different methods of producing energy from waves.[7] .The

Revised Manuscript Received on 14 August, 2019.

Dr.D.Rajalakshmi, Associate Professor, Department of Electrical and Electronics Engineering, Kumaraguru college Of Technology, Coimbatore 641049, Tamilnadu, India (Email: rajalakshmi.d.eee@kct.ac.in)

R.Priya, UG Students, Department of Electrical and Electronics Engineering, Kumaraguru college Of Technology, Coimbatore - 641049, Tamilnadu, India (Email: priyaramesh460@gmail.com)

N.Arun, UG Students, Department of Electrical and Electronics Engineering, Kumaraguru college Of Technology, Coimbatore - 641049, Tamilnadu, India (Email: arun.16ee@kct.ac.in) wave datas are recorded in various locations and analysed that annual wave energy is during monsoon period. $[8,11]$ It showed the economic and social benefits of wave energy conversion.[9] It analysed wave Characteristics based on seasonal variations in the west coast of India and showed the wave power based on seasons.[10] There are several reviews of wave energy converter (WEC) concepts. [12,13,16]

This paper proposes a technology which is based on generation of electricity with a piston (floating buoy) which moves with the waves that causes upward-downward movement of the piston which is connected to a magnet. Copper coils are mounted stationary and the magnets move within the coils when the piston moves. Based on electromagnetic induction, current is produced in the copper coils. It is the simplest and cost effective way of generating electricity from waves.

\section{PROBLEM DEFINITION AND SOLUTION}

\section{A. Existing Method}

Wave energy converter technology, particularly focusses work on being undertaken in United Kingdom. Possible activities are taken to enhance the efficiency of WEC. There is a lack of conveyance on best method of extracting energy from the waves. The LIMPET shoreline Oscillating Water Column (OWC) installed at Islay, Scotland, in 2000 represents one system that is currently producing power for the national grid [14]. In September 2008, another commercial wave power system started operating in Northern Portugal. It makes use of Pelamis power generating device. Pelamis is a floating device comprised of cylindrical hollow steel segments connected to each other by hinged joints. The wave-induced motion of these joints is resisted by hydraulic cylinders that accommodate both horizontal and vertical motion. These cylinders acts as pumps, which in turn drives an electrical generator. A wave form using Pelamis technology was recently installed in Aqucadore Wave parknear Portugal. This is a combination of hydro using waves and hence requires a number of generators to produce electricity which is the cause for its failure. [15].Hence simple system is required to overcome above problems and satisfy above requirements.

\section{B. Proposed System}

This prototype is based on the principle of electromagnetic induction by Sir Michael Faraday " Whenever there is a relative motion between the coil and the 
magnets an emf is induced which produces electricity. " This concept which is shown in Figure 1 is used effectively to generate electricity from waves in simple way. Based on Faraday law of Electromagnetic induction principle the induced voltage in the generator is $\mathrm{E}=-\mathrm{N}(\mathrm{d} \Phi / \mathrm{dt})$. It states that the induced voltage $\mathrm{E}$ in a coil proportional to the number of coil turns $\mathrm{N}$, rate of change in magnetic flux over time in which flux encloses the coil. Induced voltage depends on 3 parameters through the above simple equation. To achieve high induced voltage the system may be a) a large number of coil turns b)large flux in the magnetic circuit c) a fast change of the flux over time i.e fast motion of the translator or piston. Prototype model is designed to produce the induced voltage from the waves. The results are taken for 3 parameters mentioned above and presented .And it proves that produced voltage depend on $\mathrm{N}$, flux and speed of piston (rate of change of flux). Induced voltage increases with the above 3 parameters.

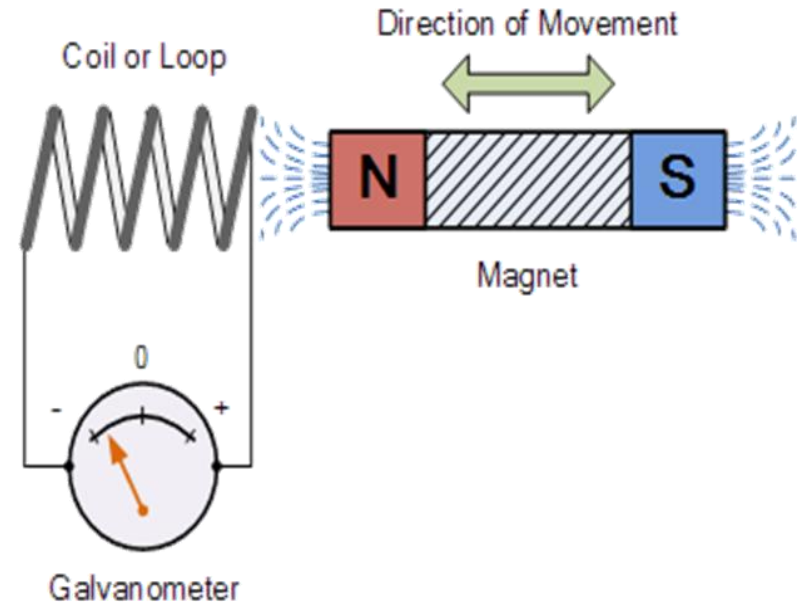

Figure 1. Principle of Faradays Law

\section{CONSTRUCTIONAL SETUP AND SPECIFICATIONS}

The proposed WEC model consists of a piston with floating buoy, permanent magnets, copper windings in a core and platform to place the components. This whole setup (platform) consists of four concrete walls with an inlet provision at the bottom of one side of the wall which allows the flow of water in and out. A floating buoy with piston arrangement is constructed which is moving up and down without difficulty corresponding to waves. The permanent magnets are placed in the piston arrangement. This whole arrangement

( floating buoy, piston attached to buoy in one end and permanent magnets placed in piston) is constructed in such a way that it is moving freely inside the core. The core is wound with number of copper coils. The copper coils are stationary whereas the magnets and piston will be at linear motion according to the waves.

Thus as the principle states, an EMF is induced across the coil when piston moves up and down. The circuit mechanism of the proto type model is shown in Figure 2.

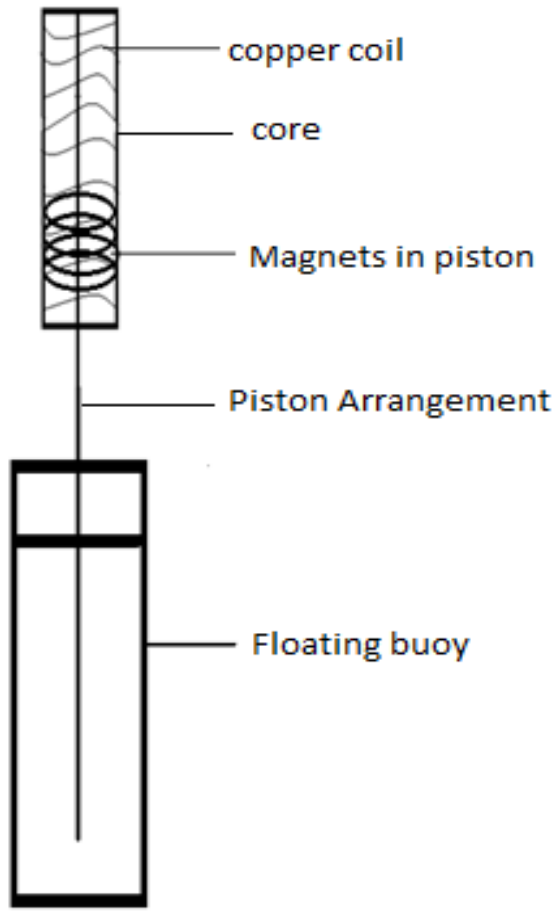

Figure 2. Mechanism

The top and front view of prototype model is designed using Autocad software and shown in Figure 3 and Figure 4.

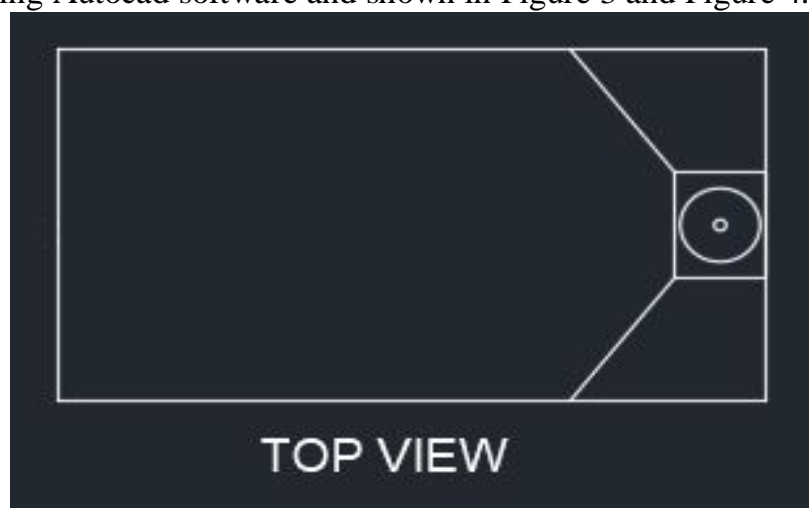

Figure 3. Top view of prototype model

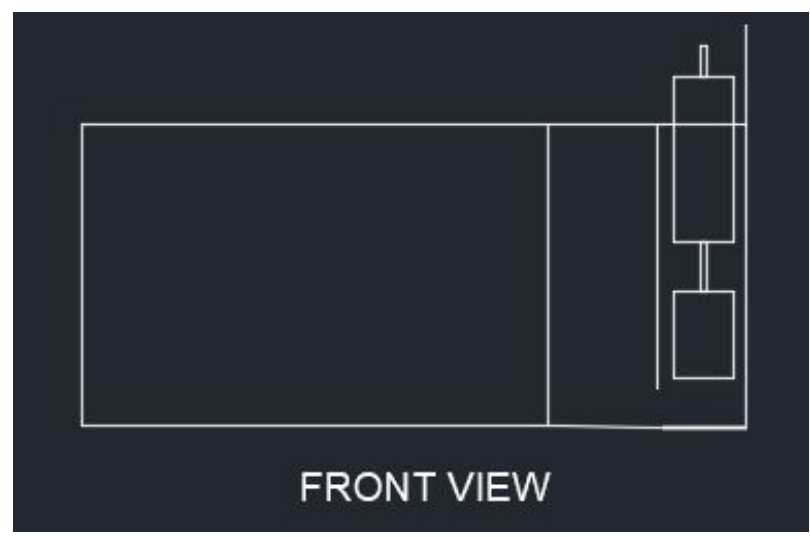

Figure 4. Front view of prototype model

The WEC arrangement is shown in Figure 5. 


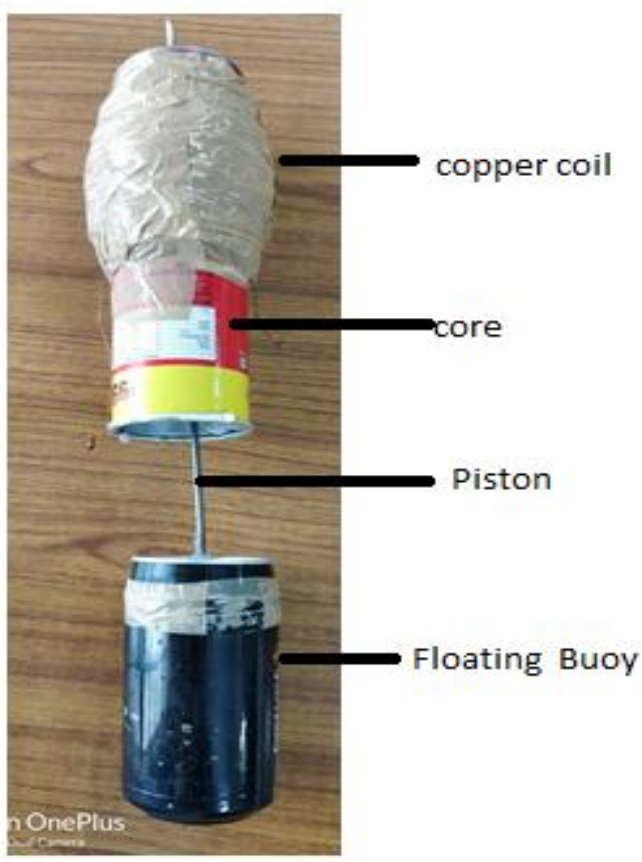

Figure 5 WEC arrangement

The whole arrangement of proposed model is shown in Figure 6.

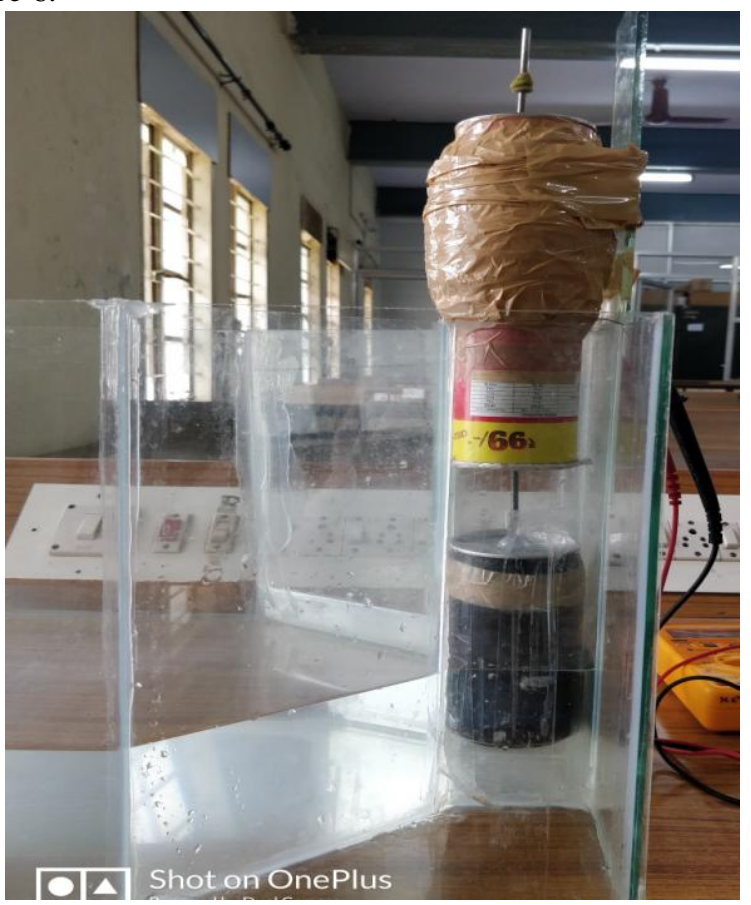

Figure 6 Hardware model

The design specifications of the proposed model are

Tank (dimensions in inches):

\begin{tabular}{|c|c|}
\hline $\begin{array}{l}\text { Tank size } \\
\text { Chamber size (to allow } \\
\text { buoy movement inside } \\
\text { the tank water) } \\
\text { WEC arrangement(dime }\end{array}$ & $: 24 * 12 * 12$ \\
\hline Total height & $: 20$ \\
\hline Floating buoy height & $: 5$ \\
\hline Floating buoy Diameter & $: 2.8$ \\
\hline $\begin{array}{l}\text { Piston arrangement } \\
\text { including core }\end{array}$ & 40 \\
\hline
\end{tabular}

\begin{tabular}{|c|c|c|}
\hline \multirow{2}{*}{\multicolumn{3}{|c|}{$\begin{array}{l}\text { Core height } \\
\text { Core Diameter }\end{array}$}} \\
\hline & \multirow{2}{*}{\multicolumn{2}{|c|}{$: 3.5$}} \\
\hline with winding & & \\
\hline Number of turns & \multicolumn{2}{|c|}{ : 1000 and 800} \\
\hline \multicolumn{3}{|c|}{ Magnet specifications: } \\
\hline \multicolumn{3}{|c|}{ Number of Rectangular } \\
\hline magnets & & sets in attracting \\
\hline & & Positions \\
\hline Magnet siz & & $: 1.2 * 0.6 * 0.4$ \\
\hline Gauss at cent & & : 11 gauss \\
\hline
\end{tabular}

\section{WORKING}

The buoy and piston arrangement which is floating on the water level is to move freely up and down due to the rising and falling of waves offshore. The resultant of this mechanical stroking changes the magnetic field. The change in magnetic field in airgap between core and piston makes the current to flow through the winding which is wound on core. This generated power can be transmitted ashore. The EMF generated depends on three important factors like number of turns in the winding and rate of change of magnetic field with time (velocity of piston). The results and its discussion are shown in next section.

\section{RESULTS AND DISCUSSIONS :}

There are number of parameters decide the induced voltage across windings. The height of up and down movement of buoy which is depending on wave height in shore and also velocity of buoy which is depending on frequency of waves inshore are taken in to considerations. The above parameters are tested for different height of piston movement and also for different velocity of piston under different number of turns of windings in the WEC The readings are shown in Figure 7 and Figure 8 for analyzing induced voltage with respect to change in height of piston (wave height) for 1000 turns and 800 turns of winding in core. It has been analyzed that increase in height of wave increases more change flux in the air gap, leads to increase in induced voltage. Increase in number of turns leads to increased induced voltage irrespective of other parameters like wave height and velocity. It is intended from the results of comparison of induced voltage for different number of turns and shown in Figure 9.

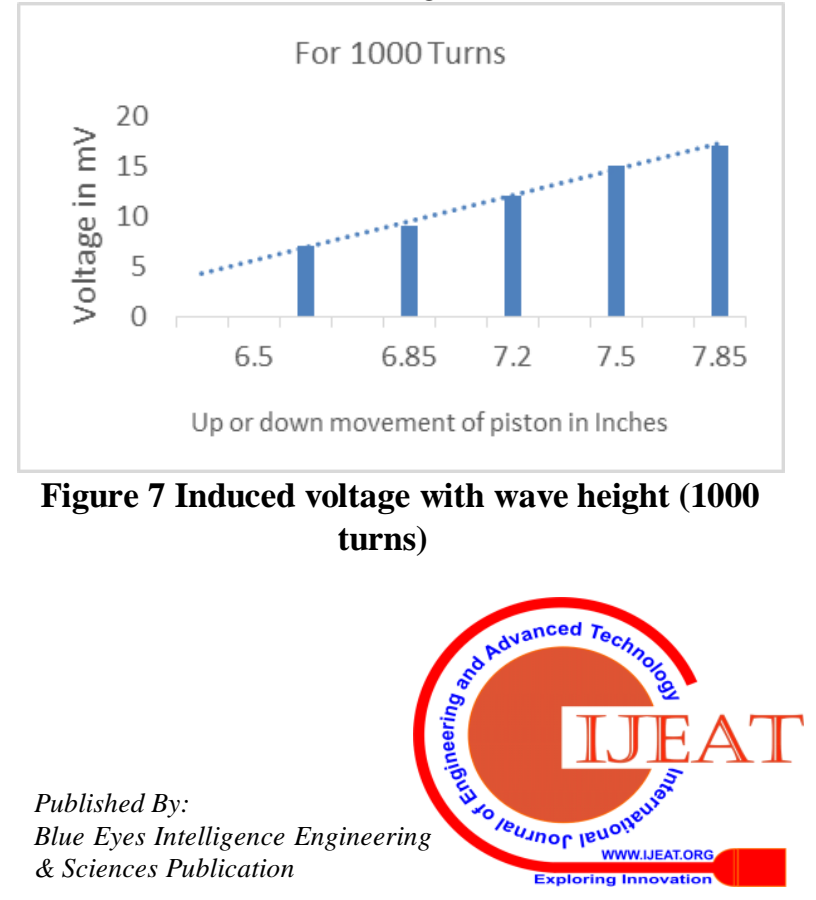




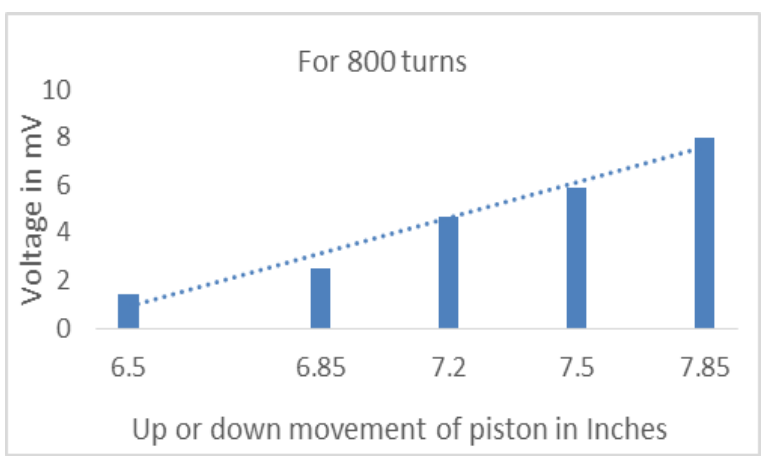

Figure 8 Induced voltage with wave height ( 800 turns)

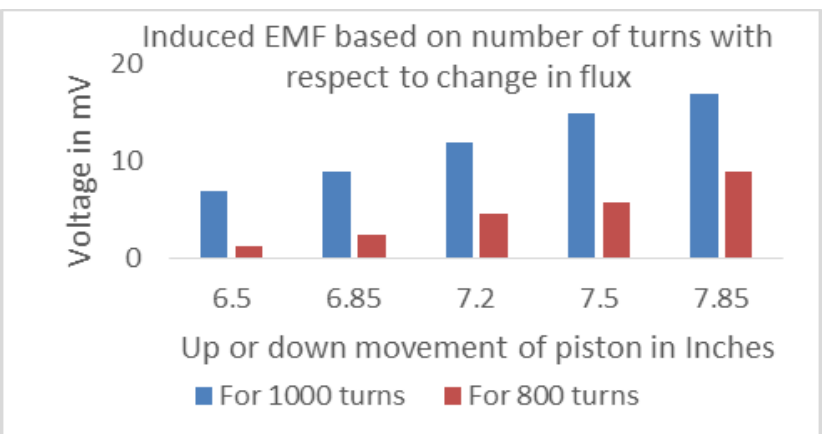

Figure 9 Comparison of voltage with wave height for different turns

The readings are shown in Figure 10 and Figure 11 for analyzing induced voltage with respect to change in piston velocity (wave velocity) for 1000 turns and 800 turns of winding in core. It has been analyzed that increase in velocity of wave increases rate of change in flux in the air gap, leads to increase in induced voltage. Increase in number of turns leads to increased induced voltage irrespective of other parameters like wave height and velocity. It is intended from the results of comparison of induced voltage for different number of turns and shown in Figure 12.

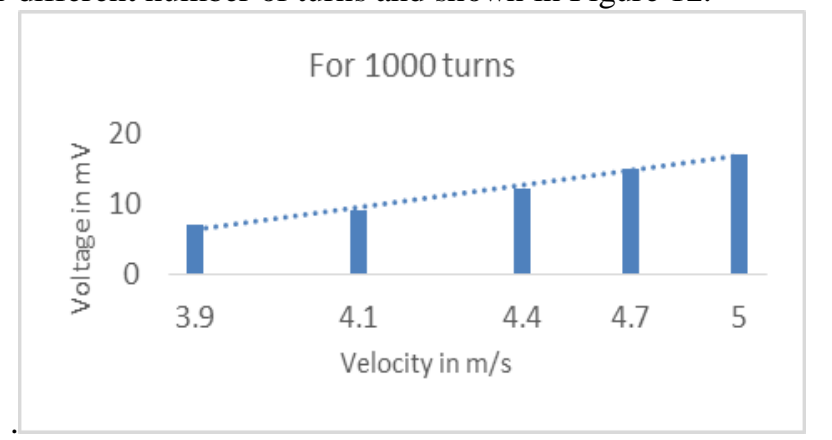

Figure 10 Induced voltage with wave velocity (1000 turns)

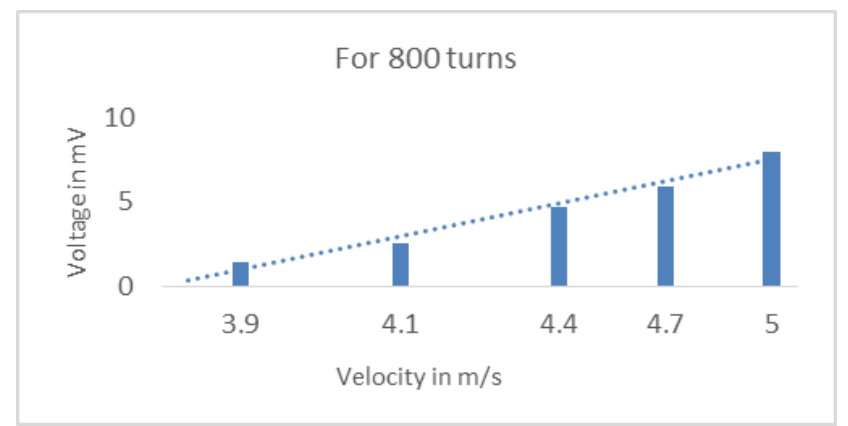

Figure 11 Induced voltage with wave velocity $(800$ turns)

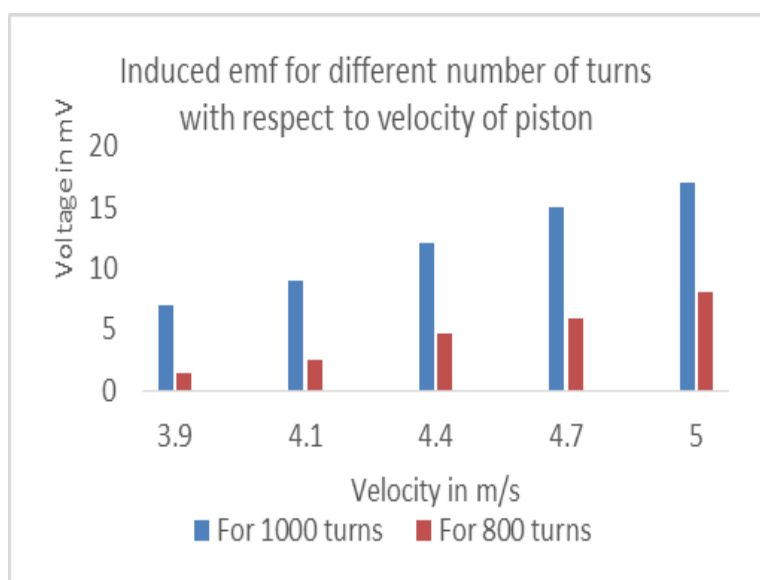

\section{Figure 12 Comparison of voltage with wave velocity for different turns}

The conditions for higher efficiency of the proposed system according to the law discussed in section I are i) Increasing the number of turns of copper coil ii) Increasing the strength of the magnets iii) Velocity of the piston. The proposed system is analyzed for most of the above factors and proved.

\section{CONCLUSION AND FUTURE SCOPE}

\section{A. Conclusion}

In today's energy powered world, a source of nonpolluting energy is hard to come upon. This proposed model describes a newer, easier and a better way of producing electricity that is cost efficient. The results are taken and analyzed for different varying parameters and presented. This setup can be implemented on the coastal areas of our state because of our long coastal line. This setup will definitely quench the need of hour-electricity. The voltage generated using this prototype can be transferred to near coastal areas.

\section{B. $\quad$ Future scope}

This system can be extended by placing sensors on the piston which will continuously monitor the performance of various subsystems and surrounding ocean environment to monitor the weather conditions. Data is transmitted to shore in real time. In the event of very large oncoming waves, the system automatically looks up and causes power production. When height of wave become normal, the system unlocks and recommences energy conversion and transmission of electrical power ashore. In future, renewable resources will be widely used and this proposal will pave as one of the best efficient renewable resource. It does not require much land area and has no damage to the land. It is ecofriendly as it does not emit or produce any toxic substances. Dependency on foreign companies for fossil fuels can be reduced if energy from wave power is extracted up to its maximum. Wave energy is consistent and proves much better than other sources. 


\section{REFERENCES}

1. Waters, R., Stålberg, M., Danielsson, O., Svensson, O., Gustafsson, S.,Strömstedt, E., Eriksson, M., Sundberg, J., and Leijon, M. "Experimental results from sea trials of an offshore wave energy system". Applied Physics Letters, 90:034105, 2007.

2. Stålberg, M., Waters, R., Danielsson, O., and Leijon, M. "Influence of Generator Damping on Peak Power and Variance of Power for a DirectDriveWave Energy Converter". Journal of Offshore Mechanics and Arctic Engineering, 130(3), 2008.

3. Eriksson, M., Waters, R., Svensson, O., Isberg, J., and Leijon, M."Wave power absorption: Experiments in open sea and simulation".Journal of Applied Physics, 102:084910, 2007.

4. Engström, J., Waters, R., Stålberg, M., Strömstedt, E., Eriksson, M.,Isberg, J., Henfridsson, U., Bergman, K., Asmussen, J., and Leijon,M. "Offshore experiments on a direct-driven Wave Energy Converter".Proceedings of the 7th European Wave and Tidal Energy Conference,EWTEC, Porto, Portugal, 2007.

5. Leijon, M., Waters, R., Stålberg, M., Svensson, O., Boström, C.,Strömstedt, E., Engström, J., Tyrberg, S., Savin, A., Gravråkmo, H.,Bernhoff, H., Sundberg, J., Isberg, J., Ågren, O., Danielsson, O.,Eriksson, M., Lejerskog, E., Bolund, B., Gustafsson, S., and Thorburn,K. "Conversion of wave motions to electricity - from theory to fullscale experiments". IEEE Power \& Energy Magazine, to appear in January 2009 issue.

6. B Drew*, A R Plummer, and M N Sahinkaya "A review of wave energy converter technology"(University of Bath, Bath, UK) 16 June 2009.

7. SajjadMehrangiza, YunusEmamia, Sayed H. SayedSadigha, Ahmad Etemadib "Various Technologies for Producing Energy from Wave" (Urmia University of Technology, Mechanical Engineering Department, Urmia, Iran).

8. Wave power potential at a few shallowwater locations around Indian coast.'CURRENT SCIENCE, VOL. 104, NO. 9,10 MAY $2013^{\prime}$

9. Marine Technology Society Journal.'Economic and Social Benefits from WaveEnergy Conversion Marine Technology'Author-Roger Bedard, Electric PowerResearch Institute-India.

10. Philip, S. C., Kumar, V. S., Johnson, G.,Dora, G. U. and Vinayaraj, P., Interannualand seasonal variations in near shore wavecharacteristics off Honnavar, west coast ofIndia. Curr. Sci. 2012, 103, 286-292.

11. Barstow, S., Gunnar, M., Mollison, D. andCruz, J., The wave energy resource inOcean wave energy (ed. Cruz, J.),Springer, Berlin, 2008, pp. 93-132.

12. http://large.stanford.edu/courses/2013/ph240/lim2/

13. Salter,S.H.Wave power nature

14. https://wiki.uiowa.edu/display/greenergy/Oscillating+Water+Co $\underline{\text { lumn }}$

15. http://en.m.wikipedia.org/wiki/Pelamis Wave Energy Convert er

16. Thorpe,T.W. A brief of wave energy

17. https://www.electronics tutorials.ws/electromagnetism/electromagnetic-induction.html 